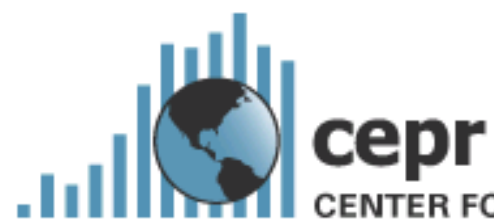

CENTER FOR ECONOMIC AND POLICY RESEARCH

\title{
The Benefits and Savings from Publicly-Funded Clinical Trials of Prescription Drugs
}

Dean Baker

March 2008

Center for Economic and Policy Research

1611 Connecticut Avenue, NW, Suite 400

Washington, D.C. 20009

202-293-5380

wwW.cepr.net 


\section{Contents}

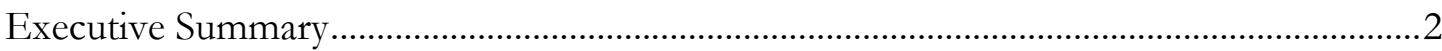

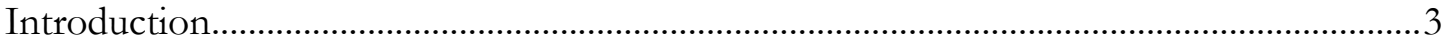

The Basic Outline: A Mechanism for Publicly Financed Clinical Trials ................................4

The Benefits of Independently Financed Drug Tests..............................................................

The Budget Arithmetic of Publicly-Funded Clinical Trials .....................................................

Efficiency Gains From Bringing Drug Prices In Line With Marginal Costs......................14

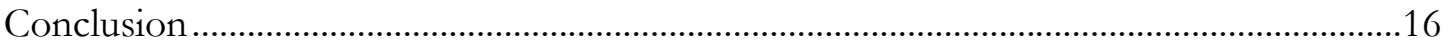

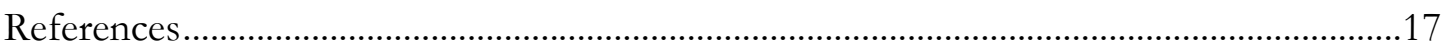

\section{About the Author}

Dean Baker is Co-Director at the Center for Economic and Policy Research in Washington, DC.

\section{Acknowledgements}

The author thanks Hye Jin Rho for research assistance and Helene Jorgensen, Mark Weisbrot, Liz Chimienti, and Meghan Morgavan for helpful comments on earlier drafts. 


\section{Executive Summary}

The current system in which prescription drug trials are financed, and often conducted directly by the company holding intellectual property rights in the drugs, leads to substantial economic inefficiency for two reasons. First, it creates an obvious conflict of interest since the party conducting the trial has a direct financial stake in the outcome. The second major source of inefficiency is that recovering the investment from the trials through higher drug prices leads to a much larger gap between drug prices and the marginal cost of production.

This paper outlines a proposal for public funding of prescription drug trials, through contracting with private sector firms to conduct trials. The cost of the trials, approximately $\$ 20$ billion in 2007 , could be more than recovered by paying lower prices for drugs purchased through the Medicare prescription drug program. This price reduction would be brought about by changing the rules on the drug program so that Medicare would negotiate prices in the same way as the Veteran's Administration. Removing the conflict of interest inherent in the current system of clinical trials and bringing drug prices closer to marginal costs would eliminate much of the inefficiency of the current system. It could also lead to substantial public health benefits.

If the public financing of drug trials is tied to a mandated reduction of 40 percent in the prices paid for drugs in the Medicare drug program (making prices paid in the Medicare program comparable to the prices paid by the Veterans Administration), the savings net of the cost of the trials over a tenyear period would be approximately $\$ 50$ billion. If state and local governments also had corresponding reductions in the prices paid for prescription drugs, their ten-year savings would be over $\$ 120$ billion. If these price reductions were applied to the private sector as well, they would total more than $\$ 900$ billion.

In addition to these potential savings, the paper describes a number of other potential benefits from a system of publicly financed prescription drug trials:

1) Publicly funded trials would eliminate the incentive and the opportunity to conceal evidence that a drug may have harmful side effects or to exaggerate evidence of the drug's effectiveness. There have been numerous instances of such behavior, as has been recently alleged in the case of efforts to conceal negative side effects associated with the pain medication Vioxx.

2) A system of publicly financed clinical trials could lead to lower costs because it would eliminate the incentive to carry duplicative drugs through the trial process in the hope of recovering sunk research costs. The current system provides this incentive even in cases where there is little reason to expect that the drug would provide any significant benefit compared with already approved drugs.

3) Publicly funded trials may be conducted at a lower cost than industry sponsored trials since there would be no incentive for independent contractors to overpay participating physicians as a way to encourage them to prescribe the company's drugs.

4) Research could advance more quickly since all the results of the trials conducted through a publicly funded system would be immediately and fully disclosed allowing other researchers to benefit from this information. 
5) Publicly funded research trials would eliminate a mechanism (data exclusivity) which is being used to obtain marketing exclusivity, and therefore raise the price of prescription drugs in many developing countries.

6) Lower drug prices would eliminate the incentive for most of the marketing done by the industry. The cost of this marketing is close to 20 percent of the sales of the prescription drug industry. It provides relatively little useful information to physicians.

7) Lower drug prices would substantially reduce the waste associated with efforts by insurers and other third party payers to restrict the use of high priced drugs. Since the third party payers can never know the circumstances as well as the doctor and patient, restrictions will inevitably result in denying drugs in some cases where the cost would be justified by benefits to the patient. Furthermore, doctors and patients have a strong incentive to find ways to circumvent any restrictions and may devote considerable resources towards this end. Sharply lower drug prices would substantially reduce the incentives for such behavior.

8) Lower drug prices would substantially reduce the incentive for patients to seek out unauthorized versions of drugs and also for manufacturers to produce counterfeit versions of expensive drugs.

\section{Introduction}

Health care professionals have long been concerned about the potential for corruption in clinical trials of prescription drugs that are sponsored by the pharmaceutical industry. Since the company sponsoring a trial has a very strong material incentive in finding positive results for its drugs, there is reason to believe that researchers carrying through drug trials may be biased and therefore may not accurately report the outcome of trials (Turner et al., 2008; Bodenheimer, 2000; Cho and Bero, 1996; Friedberg, 1998; and Stelfox, 1998).

In addition to the incentive to falsify or misrepresent research findings, the current system also suffers from other types of rent-seeking behavior that harm the public's health and raise the cost of drugs. For example, companies may carry through clinical trials even when they have little reason to expect that their drug will be better than existing alternatives. The current system provides the incentive to develop and promote copycat drugs because companies can hope to capture a portion of the patent rents earned by already approved drugs, and thereby recover a portion of sunk research costs, even if their drug is likely to provide little or no net medical benefit. The trials themselves can also provide an effective method for drug companies to convey kickbacks to physicians who prescribe their drugs, since the payment to participating physicians can be larger than is necessary to cover the cost of drug trials (e.g. see Andersen et al., 2006; Gardiner, 2004; Eichenwald and Colata, 1999a and Eichenwald and Colata, 1999b).

One way to circumvent the inefficiency and rent-seeking behavior associated with industry-funded clinical trials is to have publicly financed clinical trials. This paper outlines a proposal for publicly financed clinical trials as an alternative to industry funded trials. ${ }^{1}$ The cost of these trials could be covered by negotiating reduced payments for prescription drugs in government programs, most importantly for the drugs purchased through Medicare Part D. If Medicare reduced its payments for

\footnotetext{
${ }^{1}$ Tracy Lewis, Jerome Reichman, and Anthony So recently outlined a plan for publicly financed clinical trials (2007). While the proposal described in this paper was in large part inspired by this plan, it is not necessarily the same as the plan envisioned by these authors.
} 
prescription drugs to levels comparable to those paid by the Veterans Administration, through a comparable negotiation process, the savings would easily exceed the cost of publicly financing clinical trials. In effect, under this arrangement, the pharmaceutical industry would be compensated for lower drug prices by having the public sector pick up the cost of conducting clinical drug trials.

Reducing the price of prescription drugs, and thereby bringing drug prices closer to marginal cost, would also have substantial public health benefits. In addition to making drugs more affordable, it would also reduce the distortions that result from the large gap between price and marginal cost. This includes the time that patients and physicians spend trying to game the system to minimize drug expenditures, as well as the efforts by insurance companies and other third party payers to restrict access to costly drugs. Lower drug prices will also substantially reduce the resources devoted to marketing drugs, since the potential payoffs will be far lower. Finally, lower drug prices will reduce the incentive for patients to buy unauthorized versions of drugs, or for producers to manufacture counterfeit drugs. The large gap between drug prices and the actual production costs provide an incentive for patients and counterfeiters to take risks. ${ }^{2}$ In short, by removing the conflict of interest inherent in industry funded trials, it might be possible to achieve both better health outcomes and greater economic efficiency.

\section{The Basic Outline: A Mechanism for Publicly Financed Clinical Trials}

The central feature of this proposal is the establishment of a network of independent companies, operating on long-term federal contracts (8 to 12 years), that would be expected to replace the clinical testing currently performed and/or financed by the pharmaceutical industry. At 2008 expenditure levels, approximately $\$ 20$ billion per year would be needed to maintain a level of drug testing comparable to that currently supported by the pharmaceutical industry. This amount would rise by approximately 10 percent annually for the next decade, the same as the growth rate projected for Medicare expenditures on prescription drugs.

The agency that would actually parcel out the contracts could be either the National Institutes of Health, the Food and Drug Administration (FDA), the Centers for Medicare and Medicaid Services, or a new agency established explicitly for this purpose. The public agency administering the contracts would have the responsibility for assessing the overall efficiency and effectiveness of the prime contractors and also ensuring that contractors, and any subcontractors, adhere to ethical standards in their conduct of the trials and in the dissemination of research findings.

The firms that are contracted to do the testing would be expected to select drugs for testing based on their potential to improve public health. They would make this determination based on the evidence obtained from pre-clinical research. The oversight agency may designate that each contractor restrict itself to drugs designed for a specific class or classes of conditions, but such restrictions should not be overly narrow. A key goal of this system is to ensure that there will always be several contractors with overlapping areas of responsibility to ensure that there will be competition between them. This should reduce the probability that a potentially promising drug will be overlooked and put through clinical testing.

\footnotetext{
${ }^{2}$ In the United States, unauthorized versions of drugs are most often from foreign producers whose drugs may not meet FDA safety standards.
} 
The contractors would be expected to conduct all the tests needed to bring drugs through the FDA approval process including the three phases of clinical testing and long-term animal-testing. Since all trial results would be fully public, the various phases of clinical trials and long-term animal studies needed for FDA approval could be performed by different contractors. Any contractor would have the full benefit of the information obtained through prior round trials, not just the contractor who performed the trials. This openness should ensure competition exists at all stages of the clinical testing process and reduce the possibility that potentially beneficial drugs get bottled up in the bureaucracy of an inefficient contractor.

In order to minimize the potential for the sort of conflicts of interest that exist under the current system, it is essential that there be a strict separation between the firms that are contracted to conduct clinical trials (and any subcontractors) and the pharmaceutical companies that maintain intellectual property rights in the affected drugs. This should preclude management or employees of contracting firms from having any financial interest with the pharmaceutical companies. In addition, all contact between the pharmaceutical companies and the contracting firms should be in the form of public documents that can be easily accessed over the Internet.

For example, a pharmaceutical company that believes that it has developed a potentially promising drug, could submit its evidence to one or more of the companies contracted to conduct trials. However, all the evidence that is submitted should be placed on the Internet, so that it is fully public. Any private communications concerning drug testing should be strictly prohibited in the same way that lawyers are prohibited from discussing cases with sitting jurors.

Full disclosure rules would also apply to all trial results. All the data collected from trials should be made available on the Internet in a timely manner. This would include the full set of data available from patient questionnaires (excluding information that could compromise patients' privacy), so that other researchers could independently analyze trial results. This information would also be available for practicing physicians trying to determine the best drugs to prescribe for their patients.

The companies that sign master contracts for testing can opt to maintain control over the testing process themselves or to subcontract portions of the process to other companies. However, all the rules concerning contacts with the pharmaceutical industry and making research results accessible would apply in the same way to subcontractors as it does to prime contractors.

The funding for these tests would be appropriated by Congress at a level that should be large enough to fully replace the clinical tests performed by the pharmaceutical industry. This additional spending could be covered by having Medicare pay sharply lower prices for the drugs purchased through its prescription drug benefit. The calculations in a subsequent section of this paper assume that prices fall by 40 percent from current levels, which is roughly in line with the prices currently paid by the Veteran's Administration. While this system is not designed to prohibit privately financed clinical tests, the lower prices paid by Medicare, and possibly by other government purchasers, would apply to drugs regardless of whether or not the tests were financed through the public system. At sharply lower drug prices, it would probably not be profitable for pharmaceutical companies to pay for their own clinical trials.

\section{The Benefits of Independently Financed Drug Tests}

There are a number of benefits that can be expected from a system of publicly financed prescription drug trials. The most important benefit would be the elimination of conflicts of interest that can 
prevent the full and accurate disclosure of test results. The separation of the testing process from any intellectual property rights in the drugs being tested eliminates the incentive that exists within the current system to bias the tests in ways that exaggerate the effectiveness of drugs, and to conceal evidence of negative side effects. A strict condition for any contractor/sub-contractor is that all the results from the trials must be fully public and revealed in a timely manner. The contractors would therefore have a very strong incentive to fully disclose information, since failure to do so would result in the loss of the contract and possibly fines and penalties as well, and no incentive to conceal it. The change in the incentive structure will allow the scientific community, as well as practicing physicians, to get the full benefit of the information obtained in the trials.

There would be many additional benefits from a system of publicly financed clinical trials. One of the main benefits is that under this system fewer resources are likely to be wasted in the development of drugs that offer little net medical benefit over existing drugs. Under the current system, drug companies can hope to recover a substantial portion of their research costs by carrying a drug through the approval process, even if it has no reason to believe that the drug offers any significant benefit relative to existing drugs. If a copycat drug can win a portion of the patent rents gained by drug(s) already approved, then it may more than cover the cost of additional testing and recover some or all of its sunk research costs. ${ }^{3}$

Under the publicly financed system, the public contractors would have little motivation to test a drug in a situation where pre-clinical evidence or early phase clinical trials provided no reason to believe that the new drug would offer a substantial medical benefit compared with existing drugs. From the standpoint of the contractors, testing a drug that essentially duplicates the function of existing drugs would be a wasteful expenditure. In addition, all the testing can be designed to be explicitly comparative, using standard research methodologies so that the effectiveness of a newly tested drug can be readily measured against the effectiveness of existing drugs. In cases where a $\operatorname{drug}(\mathrm{s})$ has already been approved in the same class, the most efficient (and ethical) test of a new drug would be against a control group that was given a drug that was already approved.

In the years from 1990 to 2004, almost 80 percent of the drugs approved by the FDA fell into the standard classification, meaning that they provided no significant advance over existing drugs. ${ }^{4}$ Many of the drugs receiving standard classification probably would be still be approved under the system of publicly funded trials outlined here. In some cases, the drugs were involved in races for approval in which the success of a competing drug was uncertain. In such instances, it may be efficient to continue the testing necessary to carry a drug through the FDA approval process in order to have an additional treatment option. However, this is only likely to be the case with drugs that are already in the last stages of testing so that the marginal cost of gaining approval is relatively small.

It may also be beneficial to bring some drugs with standard classifications through the FDA approval process if the existing $\operatorname{drug}(\mathrm{s})$ are known to have harmful side effects or to react badly with other drugs that some patients may be taking. Nonetheless, the altered incentive structure of a system of publicly financed drug trials is likely to lead to a substantial reduction in the number of non-priority drugs carried through the FDA approval process. This can lead to substantial cost

\footnotetext{
${ }^{3}$ Under the current system, by providing additional potential competition, a duplicative drug may lower the cost of the competing $\operatorname{drug}(\mathrm{s})$ that are already approved. However, if prices were already pushed much closer to marginal cost, then the impact of an additional drug on prices would be expected to be considerably smaller.

${ }^{4}$ U.S. Food and Drug Administration, Center for Drug Evaluation and Research, "CDER NDAs Approved in Calendar Years 1990-2004 by Therapeutic Potential and Chemical Type" [http://www.fda.gov/cder/rdmt/pstable.htm ].
} 
savings, especially since Phase III trials (the last stage before the approval) are by far the most expensive part of the clinical testing process. ${ }^{5}$

It is worth noting that a publicly-funded system would not preclude drug companies from paying for their own trials. Since drug prices would be far lower under this system, at least for drugs purchased through public sector programs (which account for more than half of spending on prescription drugs), drug companies would have far less incentive to pay for drug trials. However, if a company was confident that its drug would offer substantial benefits over existing drugs, in spite of the refusal of the publicly financed contractors to pay for clinical trials, they would be free to do so at their own expense and submit the drug for FDA approval, just as they do now. In the event that the drug is approved, it would be priced in the same way as drugs that were tested through the publicly funded system, at least for public sector programs. This would discourage pharmaceutical companies from testing drugs that they did not believe offered significant benefits over existing drugs; however, in cases in which they believed that the publicly financed testers had overlooked an important new drug, they would still have incentive to carry through the necessary tests to gain FDA approval.

The full public disclosure of research results should also help to advance the research process. If all the information from drug trials is made fully accessible to other researchers, it will vastly increase the amount that can be learned from these trials. Researchers will be able to readily analyze data within and across studies to determine the relative effectiveness of different drugs and the frequency of side effects for specific demographic groups and for those suffering from medical conditions, in addition to the condition being treated by a specific drug. This system of full disclosure sharply contrasts with the current system under which companies release only the data that they choose and the FDA strictly prohibits sharing any data without the approval of the company that submitted it.

Another potential benefit of a publicly financed system of clinical trials is that it eliminates the potential for inappropriate payments to doctors for participating in drug trials. Under the current system of industry-financed clinical tests, payments to physicians for taking part in clinical trials can effectively include a kickback component for prescribing the company's drugs. There have been numerous news accounts of incidents in which drug companies deliberately overpaid doctors to participate in drug trials as a way of rewarding them for prescribing their drugs (e.g. Gardiner, 2004; Eichenwald and Colata, 1999a and Eichenwald and Colata, 1999b).

A recent study found that doctors who were paid to take part in clinical trials were more likely to prescribe the company's drugs after their participation than before. ${ }^{6}$ The higher propensity to prescribe the company's drugs could be due to the fact that the doctors who take part in these trials are more familiar with the company's products, but it may also be explained by the fact that participation in trials is an effective mechanism for sharing some of the rents earned from prescriptions.

The economics of this relationship are straightforward. The prescription price of a brand drug is far above the marginal cost of production. This gives the manufacturer substantial rents for each prescription issued. Kicking back a portion of this rent to the doctors who write prescriptions increases their incentive to prescribe the company's drug. Of course, outright kickbacks are illegal. However, it is not typically possible for the government to know the true market price for physicians

\footnotetext{
${ }^{5}$ Dimasi et al. (2003) estimates that Phase III tests cost 65.3 percent more than Phase I and Phase II tests combined (Table 3).

${ }^{6}$ Andersen, M., J. Kragstrup, and J. Søndergaard, 2006. How Conducting a Clinical Trial Affects Physicians' Guideline Adherence and Drug Preferences, Journal of the American Medical Association, 295: 2759-2764.
} 
taking part in the clinical trial of particular drug. Therefore, a company can typically make payments for participation that far exceed the doctor's true costs as a way to kick back a portion of their profits.

By removing any link between the company that owns a drug and the doctors who take part in trials, a system of publicly financed trials eliminates this potential abuse of the testing process. This should lead to lower cost clinical trials, since the payments should reflect doctors' actual costs. It would also eliminate the potential consequence of kickbacks from drug companies: doctors who prescribe drugs that may be inappropriate for their patients.

A system of publicly financed clinical trials would also have very large international benefits. A major source of contention in many recent trade agreements have been efforts by the United States and other wealthy countries to require developing countries to grant lengthy periods of marketing exclusivity for test data submitted to government regulatory authorities. This restriction effectively precludes generic competition for the period of exclusivity, potentially raising the price of life-saving drugs by several hundred percent above the competitive market price. In fact, the protections granted for data exclusivity are in some ways stronger than patent protection. While it is sometimes possible to innovate around a patent, conducting clinical tests on a drug that is already recognized as safe and effective would require giving placebos to a control group when it is already known that an effective treatment is available. This would violate generally accepted standards of medical ethics. While it is appropriate that other countries share with U.S. taxpayers the cost of paying for clinical trials, it is possible to devise far more efficient mechanisms for sharing these costs that do not jeopardize the life and health of people in developing countries (e.g. Hubbard and Love, 2004).

To sum up, the largest potential benefit from a system of publicly financed clinical trials would be the elimination of the incentive to misrepresent or conceal research findings. In addition, the full public disclosure of findings should facilitate the research process, leading to more progress than is possible under the existing system. There are likely to be additional benefits as well, most importantly that less money is likely to be wasted developing copycat drugs and the testing could be designed to provide a clearer basis for the comparative effectiveness of different drugs. This system should also eliminate the need to include provisions for data exclusivity in trade agreements, which have raised the price of drugs for tens of millions of people in the developing world.

\section{The Budget Arithmetic of Publicly-Funded Clinical Trials}

The target of a program for publicly financing prescription drug trials should be to essentially replace the quantity of trials that are being financed at present by the private sector with trials supported by public financing. As noted earlier, this could likely be accomplished with a somewhat smaller level of spending since trials of some duplicative drugs would probably not be conducted by a publicly financed system. Also, the per person cost of trials may be somewhat lower in a publicly financed system since there would not be a kickback component in the fees paid to doctors for their participation. However, even if some savings prove possible, the current level of spending by the industry on drug trials should provide a reasonably good target for the amount of funding that it would be necessary to appropriate in order to maintain the same pace of drug development. 
TABLE 1

Levels of Research Funding

\begin{tabular}{lccccc}
\hline \hline & $\begin{array}{c}\text { Estimate } \\
(2005)\end{array}$ & $\begin{array}{c}\text { Real } \\
\text { Growth Rate }\end{array}$ & $\begin{array}{c}\text { Implied 2007 } \\
\text { Spending }\end{array}$ & $\begin{array}{c}\text { Clinical } \\
\text { Level }\end{array}$ & $\begin{array}{c}\text { Percent of } \\
\text { Clinical R\&D } \\
\text { Replaced }\end{array}$ \\
\cline { 2 - 6 } NSF & $\$ 17 \mathrm{~b}(2003)$ & $5 \%$ & $\$ 23.7 \mathrm{~b}$ & $\$ 11.9 \mathrm{~b}$ & $168.1 \%$ \\
PhRMA & $\$ 39 \mathrm{~b}(2004)$ & $8 \%$ & $\$ 58.2 \mathrm{~b}$ & $\$ 29.1 \mathrm{~b}$ & $68.7 \%$ \\
\hline \hline
\end{tabular}

Source: Congressional Budget Office, see text.

A recent Congressional Budget Office study of research and development spending in the pharmaceutical industry reported an estimate from the National Science Foundation (NSF) that the industry spent $\$ 17$ billion (in 2005 dollars) on $R \& D$ in $2003 .^{7}$ It also reported an estimate from the Pharmaceutical Research and Manufacturers of America (PhRMA), the industry trade group, that the industry spent $\$ 39$ billion (also in 2005 dollars) R\&D in 2004. The largest single source of difference between these estimates is that the latter estimate includes post-approval research. The PhRMA estimate also includes foreign research conducted by U.S.-based companies, as well as research on processes. The NSF estimates imply a 5 percent real average annual growth rate since 1980, while PhRMA's estimates imply an 8 percent growth rate. Applying the implied growth rates to both numbers would imply spending of $\$ 21.9$ billion in 2007 using the NSF data and $\$ 52.1$ billion using the PhRMA data.

Dimasi (2003, p 166) estimates that approximately 50 percent of R\&D spending is accounted for by clinical tests as opposed to pre-clinical research. ${ }^{8}$ This implies that clinical spending in 2007 would be between $\$ 12$ billion and $\$ 26.1$ billion, depending on whether the NSF estimate or the PhRMA estimates are used. Given this range, a spending level of $\$ 20$ billion should be sufficient to replace all or most of the clinical testing currently funded by the industry as shown in Table $1 .{ }^{9}$

It is worth assessing whether a program of this size would be sufficient to finance a volume of clinical trials comparable to the number currently financed by the industry. Dimasi estimated that the average cost of a clinical trial in the mid-to-late 90 s was $\$ 29.1$ million (in 2000). ${ }^{10}$ Assuming 8 percent real growth in costs, and that the mid-point of the trials for the period examined by Dimasi was 1997, the average cost of a trial in 2007 would be approximately $\$ 79$ million. This means that a $\$ 20$ billion appropriation would be sufficient to support 253 clinical trials. With new drug approvals averaging just over 80 per year (two-thirds of which do not involve new molecular entities), this level of funding would be sufficient to support an average of 3 trials per approved drug.

It is worth noting that Dimasi's estimate of the cost of clinical trials is considerably higher than is suggested by other evidence. Love (2003) reports evidence on costs from several sources. One source, the Pharmaceutical Education and Research Institute (PERI), found average trial costs of

\footnotetext{
${ }^{7}$ These numbers can be found in Congressional Budget Office, 2006, p. 17 [http://www.cbo.gov/ftpdocs/76xx/doc7615/10-02-DrugR-D.pdf].

${ }^{8}$ This figure can be obtained by backing out his estimate that 30 percent of the cost of developing a specific drug is assumed to be attributed to pre-clinical research. Dimasi assumed that clinical spending was associated with pre-clinical research that was done on average five years earlier. Given the 11 percent nominal growth in spending that the study finds, this implies that current pre-clinical research should be approximately equal to spending on clinical research.

${ }^{9}$ Some of the post-approval testing is performed to demonstrate that a company's drug is superior to alternatives, in order to increase market share. While such comparative testing can serve a useful purpose, if the initial tests were designed to facilitate assessments of comparative effectiveness, there would be less reason for conducting such tests post-approval.

${ }^{10}$ This figure is obtained by averaging the cost of the three pre-approval trial phases as shown in Table 1 (p 162).
} 
TABLE 2

Number of Clinical Trials Supported by \$20 Billion Appropriation

\begin{tabular}{lccc}
\hline \hline & Trial Cost (2007) & Trials Supported & Trials Per Approved Drug \\
\hline Dimasi & $\$ 79.0$ million & 253 & 3 \\
PERI & $\$ 37.7$ million & 530 & 6 \\
\hline \hline
\end{tabular}

Source: Dimasi, Love, and author's calculations, see text.

TABLE 3

Number of Enrolled Patient Supported by \$20 Billion Appropriation

\begin{tabular}{lccc}
\hline \hline & Per Patient Cost & Patients Enrolled & Patients Per Approved Drug \\
\hline Dimasi (8\% growth) & $\$ 14,088$ & $1,420,000$ & 16,700 \\
Dimasi (5\% growth) & $\$ 10,270$ & $1,950,000$ & 22,940 \\
\hline \hline
\end{tabular}

Source: Dimasi, 2003 and author's calculations, see text.

$\$ 17.0$ million over roughly the same period examined by Dimasi. ${ }^{11}$ If the 5 percent real growth rate in expenses found by NSF is applied to the PERI estimates, then the average cost of trial in 2007 would be $\$ 37.7$ million. At this cost, a $\$ 20$ billion annual expenditure would be sufficient to fund 530 clinical trials a year, more than 6 trials per approved drug.

In assessing the adequacy of this level of spending, it is important to keep in mind that the twothirds of new drug approvals do not involve new molecular entities and, therefore, would not require phase I tests to determine safety. So, even with the higher cost implied by Dimasi's analysis, the proposed level of spending would likely be enough to replace all or almost of the clinical trials currently financed by the pharmaceutical industry.

Another way to assess the impact of a $\$ 20$ billion annual appropriation for clinical testing would be to calculate the number of patients who could potentially be enrolled in trials for this level of expenditure. Dimasi calculated that the average number of patients enrolled in trials in their sample was 5,303 (p177, fn 41). ${ }^{12}$ This implies a cost of $\$ 5,490$ per patient. Assuming an 8 percent real growth rate, this implies an average per person cost of $\$ 14,088$ in 2007 . At this cost, the $\$ 20$ billion appropriation would be sufficient to support trials involving 1,420,000 patients enrolled in clinical trials. If the 5 percent real growth rate derived from the NSF's estimates is used, then the average cost per patient in 2007 would be $\$ 10,270$. At this cost, the $\$ 20$ billion appropriation would be sufficient to support 1,950,000 patients enrolled in clinical trials.

While these calculations are imprecise, they suggest that a $\$ 20$ billion appropriation would be in the range of the funding needed to replace the clinical trials currently being supported by the pharmaceutical industry. Insofar as the incentives created by the current system lead to trials for drugs that provide little medical benefit, there will be less need for trials under a publicly funded system, thereby allowing for savings relative to the current system or the testing of more useful drugs. Similarly, if the current system provides incentives for overpaying doctors as an inducement to prescribe drugs, then the cost per trial and per patient will decline in a system of publicly financed trials. The reduction in per patient costs will also allow for either savings to taxpayers or for more useful drugs to be tested.

\footnotetext{
${ }^{11}$ Love 2003, Table 2.6-1. This figure attaches Dimasi's estimates of the frequency of each phase of clinical trials.
} 
TABLE 4

Spending and Savings on the Medicare Prescription Drug Plan

\begin{tabular}{lllllll}
\hline \hline & $\begin{array}{l}\text { Medicare } \\
\text { Drug Costs* }\end{array}$ & $\begin{array}{l}\text { Trial } \\
\text { Costs }\end{array}$ & $\begin{array}{l}\text { Low Saving } \\
(-40 \%)\end{array}$ & $\begin{array}{l}\text { High Saving } \\
(-60 \%)\end{array}$ & $\begin{array}{l}\text { Net Saving } \\
\text { (low) }\end{array}$ & $\begin{array}{l}\text { Net Saving } \\
\text { (high) }\end{array}$ \\
\hline 2007 & $\$ 55.0$ & $\$ 0.00$ & $\$ 0.00$ & $\$ 0.00$ & $\$ 0.00$ & $\$ 0.00$ \\
2008 & 63.9 & 0.0 & 0.0 & 0.0 & 0.0 & 0.0 \\
2009 & 70.3 & 0.0 & 0.0 & 0.0 & 0.0 & 0.0 \\
2010 & 78.4 & 0.0 & 0.0 & 0.0 & 0.0 & 0.0 \\
2011 & 86.4 & 7.9 & 8.6 & 13.0 & 0.8 & 5.1 \\
2012 & 96.6 & 17.6 & 20.3 & 30.4 & 2.7 & 12.9 \\
2013 & 107.7 & 29.4 & 32.3 & 48.5 & 2.9 & 19.1 \\
2014 & 121.6 & 44.2 & 48.6 & 73.0 & 4.4 & 28.7 \\
2015 & 136.9 & 49.8 & 54.8 & 82.1 & 5.0 & 32.4 \\
2016 & 152.5 & 55.5 & 61.0 & 91.5 & 5.5 & 36.0 \\
2017 & 169.9 & 61.8 & 67.9 & 101.9 & 6.2 & 40.2 \\
2018 & 189.2 & 68.8 & 75.7 & 113.5 & 6.9 & 44.7 \\
2019 & 210.8 & 76.6 & 84.3 & 126.5 & 7.7 & 49.8 \\
2020 & 234.8 & 85.4 & 93.9 & 140.9 & 8.5 & 55.5 \\
Total & 1773.9 & 496.8 & 547.5 & 821.2 & 50.7 & 324.4 \\
\hline \hline
\end{tabular}

Source: CBO and author's calculations, see text. *Baseline spending; in billions of current dollars.

As a practical matter, if Congress were to immediately approve a program for publicly funded clinical trials, it would take several years to get it up and running. The calculations in Table 4 assume that a program for public funding of drug trial is first put in place in 2011. The calculations assume that the $\$ 20$ billion needed to approximately cover testing costs in 2007 rises at the same rate that the $\mathrm{CBO}$ projects spending on the Medicare prescription drug program to rise. This puts the equivalent expenditure in 2011 at $\$ 31.4$ billion. It is assumed that one-fourth of this sum is spent in the first year, with the spending increased in equal increments (relative to the cost of the Medicare drug program), so that by 2014 spending is assumed to have risen to a level sufficient to replace industry-supported drug testing. ${ }^{13}$ In subsequent years, it is assumed that expenditures on clinical tests rise at the same rate as projected spending on the prescription drug plan.

The potential savings associated with the plan assume alternatively in a "low saving" and "high saving" scenario that Medicare negotiates prices that are either 40 percent or 60 percent less than what is currently paid by beneficiaries. These figures are derived from comparisons between drug prices in the United States and other wealthy countries, as well as the prices paid by the Veterans Administration. ${ }^{14}$ A savings of 40 percent against current prices would put prices at levels that are

\footnotetext{
${ }^{13}$ It is not clear that it would take four years to get a program of publicly financed clinical trials fully in place. The government will not actually be conducting the research, rather it will be contracting with private firms to oversee the process. Presumably, the prime contractors would rely on the structures that are already in place, which includes independent firms that conduct outsourced trials for the industry. It would be best not to rush a new system in place before all the problems can be uncovered, but it is important to realize that it will primarily be using a structure that already exists rather than building a new one from scratch.

${ }^{14}$ See Congressional Budget Office, 2004a , "Would Prescription Drug Importation Reduce U.S. Drug Spending?" Washington, D.C.: Congressional Budget Office [http://www.cbo.gov/ftpdocs/54xx/doc5406/04-29PrescriptionDrugs.pdf], and U.S. Department of Commerce, International Trade Commission, 2004. "Pharmaceutical
} 
TABLE 5

Economy-Wide Prescription Spending and Potential Savings*, Low Savings Scenario

\begin{tabular}{|c|c|c|c|c|c|c|c|c|c|}
\hline & \multicolumn{2}{|c|}{ Baseline Spending } & \multirow[b]{2}{*}{$\begin{array}{l}\text { State \& } \\
\text { Local }\end{array}$} & \multirow[b]{2}{*}{ Private } & \multicolumn{2}{|c|}{ Savings (Net) } & \multirow[b]{2}{*}{$\begin{array}{l}\text { State \& } \\
\text { Local }\end{array}$} & \multirow[b]{2}{*}{ Private } & \multirow[b]{2}{*}{ Total } \\
\hline & Medicare & $\begin{array}{l}\text { Other } \\
\text { Fed }\end{array}$ & & & Medicare & $\begin{array}{l}\text { Other } \\
\text { Fed }\end{array}$ & & & \\
\hline 2007 & $\$ 55.00$ & $\$ 19.80$ & $\$ 17.40$ & $\$ 137.40$ & $\$ 0.00$ & $\$ 0.00$ & $\$ 0.00$ & $\$ 0.00$ & $\$ 0.00$ \\
\hline 2008 & 63.9 & 20.8 & 18.6 & 144.3 & 0.0 & 0.0 & 0.0 & 0.0 & 0.0 \\
\hline 2009 & 70.3 & 24.6 & 20.0 & 153.4 & 0.0 & 0.0 & 0.0 & 0.0 & 0.0 \\
\hline 2010 & 78.4 & 28.1 & 21.7 & 163.3 & 0.0 & 0.0 & 0.0 & 0.0 & 0.0 \\
\hline 2011 & 86.4 & 33.4 & 23.5 & 174.1 & 0.8 & 0.0 & 2.4 & 17.4 & 20.5 \\
\hline 2012 & 96.6 & 38.8 & 25.6 & 185.6 & 2.7 & 0.0 & 5.1 & 37.1 & 45.0 \\
\hline 2013 & 107.7 & 42.6 & 27.8 & 200.7 & 2.9 & 0.0 & 8.3 & 60.2 & 71.5 \\
\hline 2014 & 121.6 & 45.1 & 30.2 & 217.2 & 4.4 & 0.0 & 12.1 & 86.9 & 103.4 \\
\hline 2015 & 136.9 & 48.4 & 32.7 & 235.6 & 5.0 & 0.0 & 13.1 & 94.2 & 112.3 \\
\hline 2016 & 152.5 & 53.9 & 35.6 & 255.6 & 5.5 & 0.0 & 14.2 & 102.2 & 122.0 \\
\hline 2017 & 169.9 & 60.0 & 38.8 & 277.3 & 6.2 & 0.0 & 15.5 & 110.9 & 132.6 \\
\hline 2018 & 189.2 & 66.9 & 42.2 & 300.8 & 6.9 & 0.0 & 16.9 & 120.3 & 144.1 \\
\hline 2019 & 210.8 & 74.5 & 45.9 & 326.4 & 7.7 & 0.0 & 18.4 & 130.6 & 156.6 \\
\hline 2020 & 234.8 & 82.9 & 50.0 & 354.1 & 8.5 & 0.0 & 20.0 & 141.6 & 170.2 \\
\hline Total & 1773.9 & 639.8 & 430.0 & 3125.8 & 50.7 & 0.0 & 126.0 & 901.5 & 1078.2 \\
\hline
\end{tabular}

Source: CBO, CMS, and author's calculations, see text. *Billions of current dollars

comparable to those paid in several other countries. A savings of 60 percent would likely lead prices that are as low, or lower, than those paid in any other wealthy country. The savings are assumed to be phased in over four years, to coincide with the ramping up of spending on clinical trials.

The low savings scenario shown in column three shows gross savings of $\$ 8.6$ billion in 2011 , the first year the program is projected to be in place, which rises to $\$ 48.6$ billion in 2014, when spending has reached a level sufficient to replace industry supported research. Savings continue to increase in step with the projected rise in Medicare drug expenditures, reaching $\$ 93.9$ billion in 2020 . In the low savings scenario, the total gross savings over the ten year period is $\$ 547.5$ billion. The net savings, after covering the costs of the clinical trials, ends up being $\$ 50.7$ billion over this ten year period.

It is important to remember that lower prices for drugs purchased under the Medicare drug plan will also lead to large savings for beneficiaries. Beneficiaries currently pay an average of almost 70 percent of the cost of drugs purchased under the program. ${ }^{15}$ Cuts in drug prices of 40 percent or 60 percent would reduce the payments by Medicare beneficiaries proportionately.

Both the gross and net savings are considerably larger in the high savings scenario, which assumes that drug prices decline by 60 percent. In this scenario, the gross savings rise from $\$ 13.0$ billion in2011 to $\$ 73$ billion in 2014 . By 2020 they are projected to be $\$ 140.9$ billion. Total gross savings

Price Controls in OECD Countries,” Washington, D.C.: U.S. Department of Commerce

[http://www.ita.doc.gov/td/health/DrugPricingStudy.pdf])

${ }^{15}$ Congressional Budget Office, 2004. "A Detailed Description of CBO's Cost Estimate for the Medicare prescription Drug Benefit” Washington, D.C.: Congressional Budget Office, Table 7

[http:/ / www.cbo.gov/ ftpdoc.cfm?index $=5668$ \&type $=0]$. 
TABLE 6

Economy-Wide Prescription Spending and Potential Savings*, High Savings Scenario

\begin{tabular}{|c|c|c|c|c|c|c|c|c|c|}
\hline & \multicolumn{2}{|c|}{ Baseline Spending } & \multirow[b]{2}{*}{$\begin{array}{l}\text { State \& } \\
\text { Local }\end{array}$} & \multirow[b]{2}{*}{ Private } & \multicolumn{2}{|c|}{ Savings (Net) } & \multirow[b]{2}{*}{$\begin{array}{l}\text { State \& } \\
\text { Local }\end{array}$} & \multirow[b]{2}{*}{ Private } & \multirow[b]{2}{*}{ Total } \\
\hline & Medicare & $\begin{array}{l}\text { Other } \\
\text { Fed }\end{array}$ & & & Medicare & $\begin{array}{l}\text { Other } \\
\text { Fed }\end{array}$ & & & \\
\hline 2007 & $\$ 55.00$ & $\$ 19.80$ & $\$ 17.40$ & $\$ 137.40$ & $\$ 0.00$ & $\$ 0.00$ & $\$ 0.00$ & $\$ 0.00$ & $\$ 0.00$ \\
\hline 2008 & 63.9 & 20.8 & 18.6 & 144.3 & 0.0 & 0.0 & 0.0 & 0.0 & 0.0 \\
\hline 2009 & 70.3 & 24.6 & 20.0 & 153.4 & 0.0 & 0.0 & 0.0 & 0.0 & 0.0 \\
\hline 2010 & 78.4 & 28.1 & 21.7 & 163.3 & 0.0 & 0.0 & 0.0 & 0.0 & 0.0 \\
\hline 2011 & 86.4 & 33.4 & 23.5 & 174.1 & 5.1 & 0.0 & 3.5 & 26.1 & 34.7 \\
\hline 2012 & 96.6 & 38.8 & 25.6 & 185.6 & 12.9 & 0.0 & 7.7 & 55.7 & 76.2 \\
\hline 2013 & 107.7 & 42.6 & 27.8 & 200.7 & 19.1 & 0.0 & 12.5 & 90.3 & 121.9 \\
\hline 2014 & 121.6 & 45.1 & 30.2 & 217.2 & 28.7 & 0.0 & 18.1 & 130.3 & 177.2 \\
\hline 2015 & 136.9 & 48.4 & 32.7 & 235.6 & 32.4 & 0.0 & 19.6 & 141.4 & 193.3 \\
\hline 2016 & 152.5 & 53.9 & 35.6 & 255.6 & 36.0 & 0.0 & 21.4 & 153.4 & 210.8 \\
\hline 2017 & 169.9 & 60.0 & 38.8 & 277.3 & 40.2 & 0.0 & 23.3 & 166.4 & 229.8 \\
\hline 2018 & 189.2 & 66.9 & 42.2 & 300.8 & 44.7 & 0.0 & 25.3 & 180.5 & 250.5 \\
\hline 2019 & 210.8 & 74.5 & 45.9 & 326.4 & 49.8 & 0.0 & 27.6 & 195.8 & 273.2 \\
\hline 2020 & 234.8 & 82.9 & 50.0 & 354.1 & 55.5 & 0.0 & 30.0 & 212.4 & 297.9 \\
\hline Total & 1773.9 & 639.8 & 430.0 & 3125.8 & 324.4 & 0.0 & 189.0 & 1352.3 & 1865.7 \\
\hline
\end{tabular}

Source: CBO, CMS, and author's calculations, see text. *Billions of current dollars.

over the ten year period are projected to be $\$ 821.2$ billion. Total net savings in the high savings scenario are $\$ 324.4$ billion over the ten year period.

The potential savings from the Medicare prescription drug program are large enough by themselves to easily cover the expense of publicly financed clinical trials. However, there could also be savings for state and local governments if the federal government designed a system in which it also negotiated lower prices on the behalf of other units of government. In principle, the government could even have lower drug prices apply to private insurance plans or a government-run plan that served the population as a whole. Table $\mathbf{5}$ shows the potential savings from having lower prices apply to other segments of the market under the "low savings" scenario.

Columns one through four show baseline projections of spending on the Medicare drug program, other federal spending on prescription drugs (largely through the Veterans Administration), state and local spending, and private sector spending, as projected by the Centers for Medicare and Medicaid Services (CMS). ${ }^{16}$ Columns five through eight show projected savings under the assumption that drug prices are reduced by 40 percent relative to the baseline. The savings shown for the Medicare drug program are net of the cost of clinical trials. The calculations assume no

\footnotetext{
${ }^{16}$ Center for Medicare and Medicaid Services, 2007. "National Health Expenditure Projections, 2006-2016." Washington, D.C.: Center for Medicare and Medicaid Services, Table 11

[http://www.cms.hhs.gov/NationalHealthExpendData/downloads/proj2006.pdf]. The projections for the "other federal government category" are obtained by subtracting the CBO projections for the Medicare drug program from the CMS projections for all federal spending. It is assumed that the growth rate from 2015 to 2016 continues through 2020 in each category of spending.
} 
savings for the "other federal government" category since the Veteran's Administration already negotiates substantial discounts with the pharmaceutical industry.

Assuming the same four-year phase-in of price reductions as in the Medicare drug plan, the savings for state and local governments rise from $\$ 2.4$ billion in 2011 to $\$ 12.1$ billion in 2014 . They rise to $\$ 20$ billion in 2020. Total savings for state and local governments over this period are projected at $\$ 126$ billion. Savings from private sector spending on prescription drugs rises from $\$ 17.4$ billion in 2011 to $\$ 86.9$ billion in 2014 . The annual savings grow to $\$ 141.6$ billion in 2020 . The total savings projected from private sector spending is $\$ 901.5$ billion. Combining savings across sectors gives a total savings of $\$ 1078.2$ billion over the ten-year period.

The high savings scenario shown in Table $\mathbf{6}$ suggests the possibility of even more dramatic savings. In this scenario, the savings to state and local governments rise from $\$ 3.5$ billion in 2011 to $\$ 18.1$ billion in 2014, reaching $\$ 30$ billion in 2030. The total projected savings for state and local governments over the ten year period is $\$ 189$ billion. Savings from private sector spending rises from $\$ 34.7$ billion in 2011 to $\$ 177.2$ billion in 2014 . The savings rise to $\$ 297.9$ billion in 2020 for a total over the period of $\$ 1,352.3$ billion over the ten year period. The total savings for all sectors in this scenario is projected at $\$ 1,865.7$ billion over the ten-year period. The savings projected for the last year are more than 1.2 percent of GDP.

\section{Efficiency Gains From Bringing Drug Prices In Line With Marginal Costs}

In addition to the directly measurable savings from lower drug prices, there will also be gains in efficiency from having drugs priced closer to their marginal cost of production, some of which could have a substantial impact on public health. The largest source of efficiency gains would be the reduction in marketing expenses that would result from lower drug prices. A recent study found that the industry's marketing expenses were equal to 18.2 percent of sales, approximately the same amount of money that the industry spends on research (Donohue et al., 2007). If drug prices were reduced by 40 to 60 percent from current levels, there would be far less incentive to spend money marketing prescription drugs. The vast majority of the marketing that currently takes place would almost certainly not be profitable at sharply lower drug prices.

While some useful information is conveyed to physicians through this marketing, it is also almost certainly the case that much misinformation is conveyed as well. The goal of marketing is to increase sales, not promote public health. Undoubtedly, there are many occasions in which sales representatives persuade physicians to prescribe their drugs in cases in which they are no better, or possibly worse, than other drugs on the market. ${ }^{17}$ It is desirable that physicians are informed about new drugs as they become available, but there are almost certainly more efficient and more effective methods than the current system. ${ }^{18}$

\footnotetext{
17 There have been many accounts of marketing abuses by the pharmaceutical industry's sales agents. For example, a recent New York Times article reported that the industry seeks out former cheerleaders to hire as its representatives (Saul, 2005).

18 Marketing also has a defensive aspect. If all companies refrain from marketing, then total sales will likely be little changed, although there would be some redistribution of sales away from those companies with the most effective marketing networks. This situation would, in general, lead to a large increase in profits for the industry as a whole. However, as soon as some firms begin to market their drugs, then other firms are forced to incur marketing expenses to protect their market share. In this way, the lower prices that prevail in a system of publicly funded clinical trials may
} 
The next most obvious efficiency gain from substantially lower drug prices would be that patients, physicians and insurers would devote less time and resources to finding ways to game rules, in the case of patients and physicians, or setting up and enforcing rules that cannot be easily gamed in the case of insurance companies. It is likely that the costs involved in gaming and policing these rules are substantial.

For example, simply the time involved in selecting among insurance plans is likely to be substantial relative to the production costs of prescription drugs. The Medicare Payments Advisory Commission found that the median amount of time that Medicare beneficiaries spent deciding on plans was eight hours (Medicare Payments Advisory Council, 2006). Assessing this time at the average hourly compensation, which was approximately $\$ 25$ an hour in 2007 , the time that the median Medicare beneficiary spent choosing plans was worth approximately $\$ 200 .{ }^{19}$ This amount is only about 7 percent of average drug expenditures under the current system, so the time may have been well invested if it allowed beneficiaries to reduce their costs. However, if drug prices were 60 percent lower, then the potential savings from different insurance options would be correspondingly reduced. As a result, it is reasonable to expect that beneficiaries would spend far less time deciding among insurance options in a system where drug prices were brought closer to marginal cost.

The time spent selecting among Medicare prescription drug plans is typical of the efforts by doctors and patients to circumvent restrictions imposed by insurance companies. There are a wide variety of mechanisms that can be employed to get around such restrictions. ${ }^{20}$ These actions may require considerable research by physicians or their staff or patients. They may also cause them to commit acts of questionable legality. If drugs were priced closer to their marginal cost, the incentive for such behavior would be substantially reduced.

Finally, the large divergence between price and marginal cost creates an incentive to seek out unauthorized versions of drugs, which are of questionable safety. This most often takes the form of buying drugs from other countries. While other wealthy countries have effective regulatory agencies that can ensure drugs meet high safety standards, this is not true for many developing countries. If patients cannot be certain of the supply network, then they may be buying drugs that are not effective or safe.

In the same vein, high drug prices also provide incentives for counterfeit drugs. This incentive exists even for the intermediaries in the industry's own supply chain, who stand to make substantial profits by either diluting drugs or substituting cheaper alternatives. In principle, this sort of counterfeiting can be restricted through careful regulation and stiff penalties, but the incentives for counterfeiting would be far smaller if drugs sold at prices that were closer to the cost of production. If drug prices grow as currently projected, then incentives for counterfeiting will increase correspondingly through time.

In short, there would be substantial efficiency gains through a variety of channels if prescription drug prices were brought down closer to the cost of production. Furthermore, since lower prices

push the industry to a scenario in which most marketing expenses are unprofitable, but the savings may leave total profits largely unaffected.

${ }^{19}$ This is taken from Mishel, Bernstein, and Allegretto (2007), Table 3.2.

${ }^{20}$ For example, a physician may prescribe a drug for a use for which an insurance company will cover the cost of a prescription, rather than for the actual use intended. Physicians may also over-prescribe drugs for a period in which the drug is covered by insurance, so that the patient can build up a supply for a period in which the drug may not be covered. 
would reduce the incentive for patients to seek out unauthorized versions of drugs, or for outright counterfeiting, lower drug price.

Furthermore, since lower prices would reduce the incentive for patients to seek out unauthorized versions of drugs, or for outright counterfeiting, lower drug prices could also have important public health dividends in addition to increasing access to drugs.

\section{Conclusion}

This paper outlines a proposal for replacing the current system of industry-financed clinical trials of prescription drugs with a system of publicly funded trials. The main benefit of this system is that it would eliminate the conflict of interest that is inherent when the party that conducts the trial has a direct financial stake in the outcome. Under plausible assumptions, a system of publicly funded trials can easily be financed by the savings from paying lower prices for prescription drugs through Medicare. In addition, the restructuring of the industry that would follow from publicly funded trials

could lead to savings on prescription drugs for the population as a whole, which would lead to substantial efficiency gains for society. 


\section{References}

Andersen, M., J. Kragstrup, and J. Søndergaard, 2006. "How Conducting a Clinical Trial Affects Physicians' Guideline Adherence and Drug Preferences," Journal of the American Medical Association, 295:2759-2764.

Bodenhiemer, 2000. "Conflict of Interest In Clinical Drug Trials: A Risk Factor For Scientific Research." Paper presented at the National Institutes of Health Conference on Conflicts of Interest in Scientific Research, August 15, 2000.

Cho MK, Bero LA. 1996. "The Quality of Drug Studies Published in Symposium Proceedings." Annals of Internal Medicine, 1996; 124:485-489.

Congressional Budget Office, 2004a , "Would Prescription Drug Importation Reduce U.S. Drug Spending?” Washington, D.C.: Congressional Budget

Office[http://www.cbo.gov/ftpdocs/54xx/doc5406/04-29-PrescriptionDrugs.pdf].

Congressional Budget Office, 2004b. "A Detailed Description of CBO's Cost Estimate for the Medicare Prescription Drug Plan,” Washington, D.C: Congressional Budget Office, endnote 11 [http:/ / www.cbo.gov/showdoc.cfm?index=5668\&sequence=2\#F11].

Congressional Budget Office, 2006. "Research and Development in the Pharmaceutical Industry," Washington, D.C: Congressional Budget Office, [http://www.cbo.gov/ftpdocs/76xx/doc7615/10-02-DrugR-D.pdf].

Dimasi J. R. Hansen, and H. Grabowski, 2003. "The Price of Innovation: New Estimates of Drug Development Costs." Journal of Health Economics, 22 151-185.

Donohue, J., M. Cevasco, and M. Rosenthal, 2007. "A Decade of Direct-To-Consumer Advertising of Prescription Drugs,” New England Journal of Medicine, August 16, 2007: 673-681.

Eichenwald, K. and G. Kolata, 1999a. "Drug Trials Hide Conflicts for Doctors," New York Times, May 16, 1999.

Eichenwald, K. and G. Kolata, 1999b. “A Doctor's Drug Trials Turn Into Fraud,” New York Times, May 17, 1999.

Friedberg, M, et al, 1998. "Evaluation of Conflict of interest in Economic Analyses of New Drugs Used in Oncology." The Journal of the American Medical Association, 1999; 282:1453-1457.

Hubbard, T. and J. Love, 2004. "A New Trade Framework for Global Healthcare R\&D." Plos Biology, V2, \#2. [http://www.plosbiology.org/plosonline].

Lewis, T, J. Reichman, and A. So, 2007. "The Case for Public Funding and Public Oversight of Clinical Trials" The Economists' Voice, V. 4 Issue 1.

Love, J. 2003. "Evidence Regarding Research and Development Investment in Innovative and NonInnovative Medicines," Washington, D.C.: Consumer Project on Technology. 
Medicare Payment Advisory Council, 2006. "How Beneficiaries Learned About the Drug Benefit and Made Plan Choices," Table 8-4, [http://www.medpac.gov/publications/congressional_reports/Jun06_Ch08.pdf].

Mishel, L., J. Bernstein, and S. Allegretto, 2007. The State of Working America, 2007-2008. Ithaca, NY: Cornell University Press.

Saul, S. 2005. "Gimme an Rx! Cheerleaders Pep Up Drug Sales," New York Times, November 28, 2005.

Stelfox Ht et al. 1998. "Conflict of Interest in the Debate over Calcium-Channel Antagonists." New England Journal of Medicine, 338:101-106.

Turner, E., A. Matthews, E. Linardatos, R.. Tell, and R. Rosenthal, 2008. "Selective Publication of Antidepressant Trials and Its Influence on Apparent Efficacy." New England Journal of Medicine, 358: 252-260.

U.S. Department of Commerce, International Trade Commission, 2004. "Pharmaceutical Price Controls in OECD Countries," Washington, D.C.: U.S. Department of Commerce [http://www.ita.doc.gov/td/health/DrugPricingStudy.pdf]).

U.S. Food and Drug Administration, Center for Drug Evaluation and Research, "CDER NDAs Approved in Calendar Years 1990-2004 by Therapeutic Potential and Chemical Type” [http://www.fda.gov/cder/rdmt/pstable.htm ]. 